\title{
Self-medication during Covid-19 pandemic: challenges and opportunities
}

\author{
Muna Malik $^{1,2} \cdot$ Muhammad Junaid Tahir $^{1,2} \cdot$ Razia Jabbar $^{1,2} \cdot$ Ali Ahmed $^{3}$ (D) Rabia Hussain $^{4}$
}

Published online: 3 October 2020

C) Springer Nature Switzerland AG 2020

\section{Self-medication (SM) during COVID-19}

The World Health Organization (WHO) defines self-medication (SM) as the selection and utilization of medicines to treat self-recognized symptoms or ailments without consulting a physician [1]. It also includes the usage or re-usage of previously prescribed or unused drugs, direct purchasing of prescription drugs without consultation, and irrational use of over-the-counter (OTC) drugs [2]. SM is a significant concern globally, affecting both developed and developing countries [3, 4]. Various studies have indicated that SM is a common practice, with a prevalence of $32.5-81.5 \%$ worldwide [5]. The most commonly self-prescribed medications are analgesics, antipyretics, antitussives, antidiarrheals, calcium and vitamin supplements, anabolic steroids, sedatives, certain antibiotics, and many herbal and homeopathic remedies [3]. As of September 21, 2020, there were 30,905,162 confirmed cases of COVID-19 [6], and, to date, no definitive treatments or vaccines are available to treat or prevent this viral infection. This situation has increased the influence of social media regarding misinformation about medications, leading to public confusion and panic and increased use of $\mathrm{SM}$, including home remedies, without established safety and efficacy $[7,8]$.

Ali Ahmed

ali.ahmed@monash.edu

1 Lahore General Hospital, Ferozpur Road, Near Chungi Amar Sidhu Ismail Naga, Lahore, Punjab, Pakistan

2 Ameer-ud-Din Medical College, Affiliated with University of Health Sciences, Lahore, Punjab, Pakistan

3 School of Pharmacy, Monash University, Jalan Lagoon Selatan, Bandar Sunway, 47500 Subang Jaya, Selangor, Malaysia

4 Department of Social and Administrative Pharmacy, Universiti Sains Malaysia, 11800 Gelugor, Pulau Penang, Malaysia
Between 7 January 2020 and 1 June 2020, the increase in people's interest in online SM information during the COVID-19 pandemic is reflected in the Google trend for searches on SM [9]. Suggestions of SM for COVID-19 may come from friends, family, neighbors, pharmacists, previous prescriptions, and the media. In developing countries, such as India, the use of SM with hydroxychloroquine and chloroquine without a prescription to prevent COVID-19 has been documented [12]. Later, the US Food and Drug Administration (FDA) declared the use of hydroxychloroquine and chloroquine as being unsafe in mild-to-moderate COVID19 based on their therapeutic safety profile in COVID-19 patients [13]. Similarly, while UK researchers have declared dexamethasone to be a 'life-saving drug' in the treatment of severe COVID-19, the UK Minister of the National Health Service stressed that dexamethasone should only be used in critically ill patients and should not be used as an SM in mild to moderate cases due to its inherent safety problems [14].

Ivermectin is sold OTC in some countries, and people are self-medicating and, more concerningly, self-dosing it for the treatment of COVID-19. Therefore, the WHO has provided several warnings to observe caution when using SM to treat COVID-19, including the irrational use of antibiotics, herbal remedies, and other OTC drugs [15]. Many herbal drugs have been used to treat COVID-19 in China, Pakistan, and other countries worldwide. Such products are readily available to the public without a prescription and are used as SM to avoid hospital visits and admissions, but their use in COVID-19 lacks evidence-based support [7]. In China, three patented herbal products (Lianhuaqingwen capsules and Jinhua Qinggan granules to treat mild conditions, and Xuebijing for severe conditions) were recommended to treat COVID-19. However, their potential effectiveness and safety needs to be confirmed by the results of randomized controlled clinical trials before being used to treat COVID19 [7]. Similarly, there was increased demand and use of Sanna Makki, a herbal plant, by local people in Pakistan due to its claimed efficacy in treating COVID-19 symptoms [16]. 
SM is considered as a part of the more extensive self-care process, which motivates individuals to undertake activities related to health improvement, treatment of illness, disease prevention, and restoring health after injury or disease [17]. SM helps to decrease the economic burden on patients, the healthcare system, third-party government agencies, and insurance companies [4]. However, the consequences of inappropriate and unnecessary SM cannot be understated, as SM may lead to polypharmacy, incorrect diagnosis, adverse effects, drug interactions, antibiotic resistance, and increased drug expenses $[2,3,10]$. Healthcare policymakers prefer to promote law and policies in favor of prescribed drug use, but the challenges associated with SM in the general population cannot be ignored [18]. Thus, improved public awareness and education about the safe and rational use of drugs are necessary to overcome the challenges of SM.

\section{Controlling SM in the COVID-19 era}

According to the WHO guidelines on SM, individuals should know the medication's method of use, efficacy, and adverse effects and their management [1]. The practice of SM should be monitored appropriately, particularly in lowand middle-income countries, which are facing an economic crisis and often have low educational standards and inadequate healthcare facilities, especially during COVID-19 [11]. SM, during the COVID-19 pandemic, can aggravate the current situation of a health crisis for which no country is fully prepared [19]. A holistic approach should be taken to improve the use of SM through public education, sound training of healthcare professionals, including community pharmacists, and strict pharmaceutical regulations on public advertising and drug use. Positive support from national health authorities will reduce the potential risk of SM and reduce the stockpiling of drugs during this pandemic [18, 19]. The authorities should provide proper strategies for drug usage. Readily available, cost effective, and proper consultation with healthcare providers should be encouraged to alleviate SM practices and to promote rational use of medicine by the public $[16,20]$. Mass media should be utilized to target general public awareness and education programs created regarding the proper use of medicines and possible risks regarding their inappropriate use; every campaign should be evaluated for its usefulness [21].

\section{Conclusion}

SM has become an essential area within healthcare, but the provision of SM is an overall major global concern, especially during the COVID-19 pandemic. SM may facilitate better healthcare with reduced prescribing drug costs.
However, inappropriate SM can lead to an incorrect diagnosis, serious adverse effects, drug interactions, drug dependence, and microbial resistance. Thus, there is a dire need to control and manage appropriate SM practices by applying strong legislation and involving healthcare professionals and policy makers.

\section{Take-home messages}

- During health crises, such as the COVID-19 pandemic, people should seek advice from health experts before using any remedy.

- The use of self-medication could be improved by educating the public about the harmful effects of irrational drug use.

\section{Declarations}

Funding No sources of funding were received for preparing this manuscript.

Conflict of interest Muna Malik, Muhammad Junaid Tahir, Razia Jabbar, Ali Ahmed, and Rabia Hussain have no relevant conflicts of interest.

Ethics approval Not applicable.

Consent to participate Not applicable.

Consent for publication Not applicable.

Availability of data and material Not applicable.

Code availability Not applicable.

Author contributions AA conceived the idea, MM, RJ, MJT, and AA retrieved the data and wrote the manuscript, AA and RA reviewed the manuscript and provided comments. All authors approved the final version of the manuscript.

\section{References}

1. World Health Organization. Guidelines for the regulatory assessment of medicinal products for use in self-medication. Geneva: World Health Organization; 2000.

2. Eticha T, Mesfin K. Self-medication practices in Mekelle, Ethiopia. PLoS ONE. 2014;9(5):e97464.

3. Afridi MI, Rasool G, Tabassum R, et al. Prevalence and pattern of self-medication in Karachi: a community survey. Pak J Med Sci. 2015;31(5):124-5.

4. Noone J, Blanchette CM. The value of self-medication: summary of existing evidence. J Med Econ. 2018;21(2):201-11.

5. Kassie AD, Bifftu BB, Mekonnen HS. Self-medication practice and associated factors among adult household members in Meket 
district, Northeast Ethiopia, 2017. BMC Pharmacol Toxicol. 2018;19(1):15.

6. World Health Organization. WHO Coronavirus Disease (COVID19) Dashboard. https://covid19.who.int/?gclid=CjwKCAjwkd L6BRAREiwA-kiczFVgD9G2jqjziCEtALuFBCwLGVS3hXLf iP4Fcvpq4nPcz8cwu1G8SRoCs8kQAvD_BwE. Accessed 21 Sep 2020

7. Yang Y. Use of herbal drugs to treat COVID-19 should be with caution. Lancet. 2020;395(10238):1689-90.

8. Erku DA, Belachew SA, Abrha S, et al. When fear and misinformation go viral: Pharmacists' role in deterring medication misinformation during the 'infodemic' surrounding COVID-19. Res Social Adm Pharm. 2020;:S1551-7411(20):30455-61.

9. Onchonga D. A Google Trends study on the interest in self-medication during the 2019 novel coronavirus (COVID-19) disease pandemic. Saudi Pharm J. 2020;28(7):903-4.

10. Azami-Aghdash S, Mohseni M, Etemadi M, et al. Prevalence and cause of self-medication in Iran: a systematic review and metaanalysis article. Iran J Public Health. 2015;44(12):1580-93.

11. Al-Worafi YM. Drug safety in Yemen. In: Al-Worafi Y, editor. Drug safety in developing countries: achievements and challenges. Chennai: Elsevier Inc.; 2020. p. 391-405.

12. Chauhan V, Galwankar S, Raina S, et al. Proctoring hydroxychloroquine consumption for health-care workers in India as per the revised national guidelines. J Emerg Trauma Shock. 2020;13(2):172-3.

13. US Food and Drug Administration. FDA cautions against use of hydroxychloroquine or chloroquine for COVID-19 outside of the hospital setting or a clinical trial due to risk of heart rhythm problems. July 1, 2020; https://www.fda.gov/drugs/drug-safet $\mathrm{y}$-and-availability/fda-cautions-against-use-hydroxychloroquineor-chloroquine-covid-19-outside-hospital-setting-or. Accessed 3 Aug 2020

14. Johnson RM, Vinetz JM. Dexamethasone in the management of COVID-19. BMJ. 2020;370:m2648.

15. World Health Organization. Coronavirus disease (COVID-19) advice for the public: mythbusters. https://www.who.int/emerg encies/diseases/novel-coronavirus-2019/advice-for-public/mythbusters. Accessed 6 Sep 2020

16. The Nation. Governor encourages herbal remedies to treat COVID-19. https://nation.com.pk/18-May-2020/governor-encou rages-herbal-remedies-to-treat-covid-19. Accessed 23 Aug 2020

17. Hughes CM, McElnay JC, Fleming GF. Benefits and risks of self medication. Drug Saf. 2001;24(14):1027-37.

18. Atif M, Malik I, Asif M, et al. Drug safety in Pakistan. In: AlWorafi Y, editor. Drug safety in developing countries: achievements and challenges. Chennai: Elsevier Inc.; 2020. p. 287-325.

19. Mallhi TH, Khan $\mathrm{YH}$, Alotaibi NH, et al. Drug repurposing for COVID-19: a potential threat of self-medication and controlling measures. Postgrad Med J. 2020;postgradmedj-2020-138447.

20. Hussain R, Dawoud DM. Drive-thru pharmacy services: a way forward to combat COVID-19 pandemic. Res Soc Adm Pharm. 2020;:S1551-7411(20)30601-X.

21. Alhomoud F, Aljamea Z, Almahasnah R, et al. Self-medication and self-prescription with antibiotics in the Middle East-do they really happen? A systematic review of the prevalence, possible reasons, and outcomes. Int J Infect Dis. 2017;57:3-12. 